\title{
Shear strengthening of reinforced concrete beams using fibre reinforced polymers (FRP)
}

\author{
Albert Alzate* - Ángel Arteaga* - Ana de Diego* \\ Ricardo Perera** \\ * Eduardo Torroja Institute for Construction Sciences-CSIC \\ Serrano Galvache, 4. 28033 Madrid, Spain \\ albert.alzate@ietcc.csic.es \\ ** ETS Ingenieros Industriales-Technical University of Madrid \\ José Gutiérrez Abascal, 2. 28006 Madrid, Spain
}

ABSTRACT. Numerous studies have been carried out and various guidebooks published in the area of strengthening of structures using composite materials, showing a great improvement in the external bending strengthening, while the same does not occur in the area of shear strengthening, which is a more complex issue to deal with. In this particular area there still remain many questions to be answered. This document shows the current approach to the shear stress analysis and its limitation, as well as the process of an experimental and theoretic research on reinforced concrete beams with external FRP strengthening. The aim of this research is to make a step forward towards better understanding of interaction mechanisms between the external and internal reinforcement and the concrete.

RÉSUMÉ. On a effectué de nombreuses études et plusieurs guides ont èté publiés dans le secteur du renforcement de structures en utilisant les matériaux composés. Ils montrent que cette technique permet une grande amélioration du comportement à flexion de poutres. Il semble en être de même pour le renforcement à effort tranchant mais, dans ce cas, de nombreuses questions restent sans réponse. Cet article montre le rapprochement actuel à l'analyse d'effort tranchant et ses limitations, ainsi qu'une recherche théorique et expérimentale sur les poutres de béton renforcées avec FRP externe. L'objectif particulier de cette recherche est la meilleure compréhension des mécanismes de l'interaction entre les renforcements externe et interne.

KEYWORDS: concrete, FRP, sear, strengthening, experimental test.

MOTS-CLÉS: béton, FRP, effort tranchant, renforcement. 


\section{Introduction}

In recent years the interest in the maintenance of building and civil works together with the increasing requirements for strength and durability have turned structures strengthening into an activity of great relevance that consumes an ever increasing percentage of resources used in construction. This trend has boosted the search for new solutions, both efficient and durable, that should help the structures adapt to these new requirements. It is within this context that the methods of external strengthening of structures based on Fibre Reinforced Polymers (FRP) have appeared, due to their excellent mechanical properties, particularly strength and stiffness, beside others, such as corrosion resistance, adaptability to the structure shape and low weight that allow their easy and fast application, causing the least possible trauma in the structure performance.

Research carried out to date has enabled the establishing of a well-defined and widely accepted procedure, laid out in codes, related to bending analysis. However, the same does not hold true for shear reinforcement and although it has been established that strengthening using FRP is an efficient system to increase the ultimate shear stress capacity, the proposed theoretic models have been varied and controversial. Nevertheless, the qualities of this material encourage many research groups in different countries to devote their efforts to the study of this topic.

\section{Shear strengthening using composite materials}

\subsection{Shear strength of reinforced concrete}

It is admitted, and it is so stated in the codes, that the capacity of a reinforced concrete cross section is determined by the separate contribution of each individual material in the following way:

$$
V=V_{c}+V_{s}
$$

where $V_{c}$ and $V_{s}$ are the contributions made by the concrete and the transverse reinforcement, respectively.

The different mechanism that explain the shear strength of the concrete in the reinforced concrete members (shear stresses on concrete without cracking; shear transference on the crack contact surface; dowel effect; arch effect; and residual tensile stresses), are synthesized in the Model code 1990 (CEB-FIB, I993) in an empirical formula based on the Zsutty equation (1971), bearing in mind the size effect, where $b$ and $d$ are the width and effective depth of the cross section respectively, $a_{s}$ is the shear span, $\rho_{s}$ is the steel ratio, $f_{c k}$ is the characteristic value of the concrete compressive strength and $\sigma_{c d}=N_{d} / A_{c}, N_{d}$ being the factored axial force that includes the prestress force and $A_{c}$ the cross sectional area of the concrete. 


$$
\frac{V_{c}}{b \cdot d}=0.12 \cdot\left(1+\sqrt{\frac{200}{d}}\right) \cdot\left(\frac{3 \cdot d}{a_{s}}\right)^{1 / 3}\left(100 \cdot \rho_{s} \cdot f_{c k}\right)^{1 / 3}-0.15 \cdot \sigma_{c d}
$$

For the contribution of transverse reinforcement, most codes and standards work with formulas derived from Mörsch's truss. This model suggests that the member acts as a structure articulated in pieces, under a positive bending moment that allows us to reach the following expression:

$$
V_{s u}=\frac{A_{s} \cdot f_{y} \cdot z}{s} \cdot(\cot \alpha+\cot \theta) \cdot \sin \alpha
$$

where $\theta$ and $\alpha$ are the inclination of the crack and the transverse reinforcement respectively, $A_{\mathrm{s}}$ the area of transverse steel, $f_{y}$ the yield point and $z$, the mechanical arm.

\subsection{Shear strengthening of reinforced concrete members using FRP}

It has been proved in lab tests and actual applications that the use of FRP as external shear strengthening significantly increases the capacity of the members to resist these stresses.

The most frequent strengthening configurations can be put together the following three schemes: lateral sides reinforcement (side bonding), U-shaped reinforcement (U-wrapped) and the reinforcement that wraps the whole cross section (complete wrapping), the fibres being arranged in all cases either perpendicularly or at $45^{\circ}$ to the beam axis.

The failure of reinforced beams is generally produced due to FRP rupture or delamination, which in this case may be due to:

- plate/sheet debonding in the plate-adhesive interface;

- plate/sheet debonding in the adhesive-concrete interface;

- concrete cover separation.

The failure mode depends essentially on the FRP bonding length. However, there is no admitted expression that allows obtaining the bonding length with sufficient reliability.

As with reinforced concrete, it is commonly accepted that shear stress in members externally strengthened with FRP is produced by the sum of individual contributions of each material, thus:

$$
V=V_{c}+V_{s}+V_{f} \text { with } V_{f}=\text { FRP contribution to shear capacity }
$$

There are different proposals for the evaluation of the strength contribution by FRP strengthening with different approaches aimed at obtaining the formulation. We may consider three, as being the representative ones: 
- the one proposed by the FIB (2001):

$$
V_{f}=0.9 \cdot \varepsilon_{f t, e} \cdot E_{f u} \cdot \rho_{f} \cdot b_{w} \cdot d \cdot(\cot \theta+\cot \alpha) \cdot \sin \alpha
$$

- the one proposed by Monti worked out analytically (Monti et al., 2006):

$$
V f=\frac{1}{\gamma_{R d}} \cdot 0.9 \cdot d \cdot f_{j e} \cdot 2 \cdot t_{f} \cdot(\cot \theta+\cot \alpha) \cdot \frac{w_{j}}{p_{f}}
$$

- and the one proposed by Teng (Teng et al., 2002), which is empirical, obtained from the analysis of test results in the available literature:

$$
V_{f}=2 \cdot f_{f e} \cdot t_{f} \cdot w_{f} \cdot \frac{h_{f e} \cdot(\sin \alpha+\cos \alpha)}{s_{f}}
$$

where, $b_{w}$ is the web width, $\varepsilon_{f d, e}$ is the design value of effective FRP strain, $f_{f e}$ is the effective stress in the FRP, $E_{f u}$ is the elastic modulus of FRP in the principal fibre orientation, $\rho_{f}$ is the FRP reinforcement ratio, $t_{f}$ and $w_{f}$ are thickness and width of the FRP sheet, $\theta$ is the angle of diagonal crack, $\alpha$ is the angle of the fibre orientation and $\mathrm{S}_{\mathrm{f}}$ is the centre-to-centre spacing of FRP plates.

The development of practical and reliable design equations for the external shear strengthening with FRP in reinforced concrete members is hindered by three aspects that have not yet been entirely understood (Monti and Liotta, 2006):

- the shear strength mechanism developed when FRP plates/sheets are adhered to the member only laterally;

- the correct evaluation of the contribution of the external strengthening with transverse FRP to the shear capacity;

- the correct evaluation of the interaction between concrete, steel and FRP contributions, since there is no guarantee that the concrete and the steel may reach their maximum strength in the presence of FRP.

\section{Research poject}

In order to increase the knowledge of the performance of this system of strengthening that has so much practical interest, a project is underway by both IETcc and Technical University of Madrid, financed by Ministry of Public Works. This project proposes a theoretical study, cross-referenced with the appropriate experimental program, that may allow the deepening of the comprehension of the mechanisms developed by FRP to collaborate in the shear strength of the reinforced concrete member, according to the different repair methods used and thus propose analytic and/or numerical models for different repair ways that may lead to the elaboration of a consistent proposal for the analysis of shear strengthening. 


\subsection{Test pogram}

The program includes the testing of fourteen $4.5 \mathrm{~m}$ long reinforced concrete test beams with insufficient reinforcement to resist shear stress (Figure 1) they are to be exposed to, for which reason external strengthening of different configurations would be necessary. Table ! contains the test scheme.

Table 1. Test scheme

\begin{tabular}{|c|c|c|c|c|c|}
\hline Series & $\begin{array}{c}\text { Fibre } \\
\text { amount }\left[\mathrm{g} / \mathrm{m}^{2}\right]\end{array}$ & Configuration & $\begin{array}{c}\text { Fiber } \\
\left.\text { orientation [ }{ }^{\circ}\right]\end{array}$ & $\begin{array}{c}\text { Spacing } \\
{[\mathrm{mm}]}\end{array}$ & $\begin{array}{c}\text { Number of } \\
\text { beams }\end{array}$ \\
\hline 1 & 0 & - & - & - & 2 \\
\hline 2 & 530 & $U$ & 90 & 0 & 2 \\
\hline 3 & 530 & $U$ & 90 & 200 & 2 \\
\hline 4 & 530 & $U$ & 45 & 200 & 1 \\
\hline 5 & 530 & $\mathrm{~W}$ & 90 & 200 & 1 \\
\hline 6 & 300 & $\mathrm{U}$ & 90 & 0 & 2 \\
\hline 7 & 300 & $\mathrm{U}$ & 90 & 200 & 2 \\
\hline 8 & 300 & $\mathrm{U}$ & 45 & 200 & 1 \\
\hline 9 & 300 & $\mathrm{~W}$ & 90 & 200 & 1 \\
\hline
\end{tabular}

In accordance with the above table, the following nomenclature is adopted: The first two characters indicate the number of beams, thus V1 means beam 1; the third letter indicates the typology in the following manner: $P$ stands for the reference beam (without strengthening) and $\mathrm{U}$ or $\mathrm{W}$, depending on the strengthening scheme: U-wrapping, or Complete wrapping; the next two indicate the main orientation angle of the fibres with respect to the longitudinal axis of the beams; the following character indicates whether the strengthening is placed with spacing (S) or it is continuous (C); The following number indicates the weight for square meter of FRP and finally the letter in brackets indicates whether the beam at issue is a long (L) or short (C) span one, since two tests are carried out with each beam as explained further on in Sub-Section 3.4.

\subsection{Test specimens}

The dimensions of the beams are as follows: length, $4500 \mathrm{~mm}$, width, $250 \mathrm{~mm}$ and height, $420 \mathrm{~mm}$. The bottom longitudinal reinforcement consists of $6 \$ 20 \mathrm{~mm}$ bars arranged in 2 layers with 4 bars in the first layer and 2 in the second one, the top longitudinal reinforcement is made of $2 \phi 10 \mathrm{~mm}$ and the shear reinforcement consists of $\phi 8 \mathrm{~mm}$ stirrups, placed at a spacing of $380 \mathrm{~mm}$ (Figure 1). 


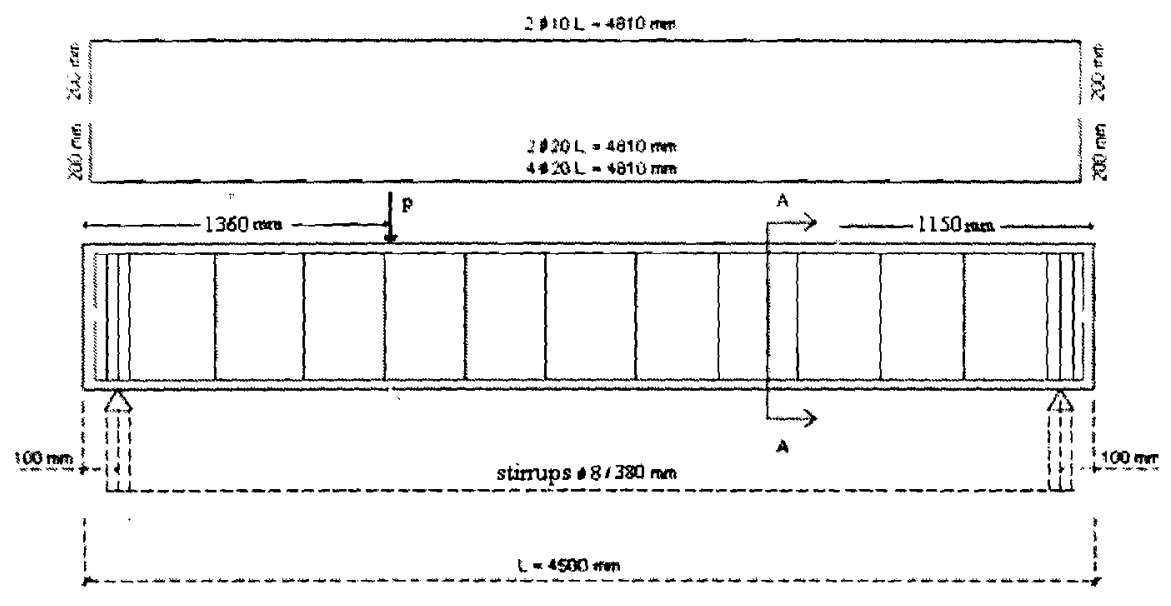

Figure 1. Beams reinforcement

The beams are strengthened by a unidirectional carbon fibre sheet adhered to the beam my means of epoxy resin, forming a laminate of the following characteristics: $300 \mathrm{~mm}$ wide, $1 \mathrm{~mm}$ thick, the tensile strength of $700 \mathrm{~N} / \mathrm{mm}^{2}$ and a $63 \mathrm{kN} / \mathrm{mm}^{2}$ elastic modulus. Figure 2 shows the different configurations of the strengthening used.

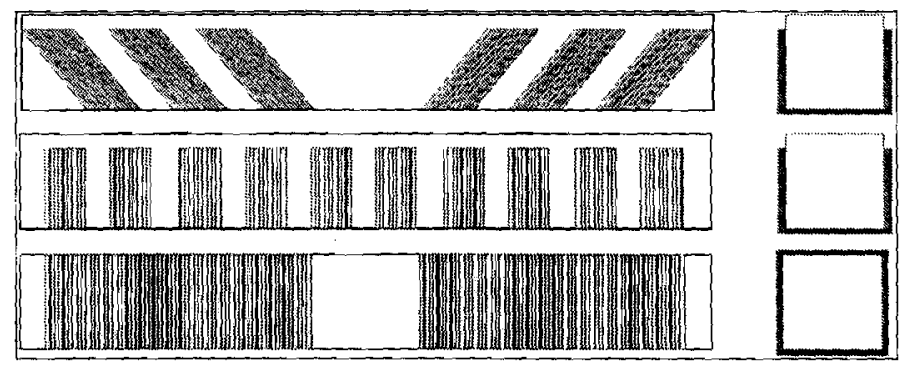

Figure 2. Reinforcement schemes

In order to avoid the early FRP failure, the beam has rounded corners with a $25 \mathrm{~mm}$ radius, which was achieved during manufacturing by placing concave wooden wedges in the frameworks.

Before bonding the sheet, the beam surface is prepared, removing the top cement layer by using a sand jet and cleaning the resulting waste in order to guarantee a greater bonding between the concrete and the FRP. 


\subsection{Instrumentation}

Each beam is equipped with strain gauges placed on the steel stirrups $(2$ per stirrup) in the areas along which the crack is supposed to pass and gauges on the FRP sheet in the shear area. Figure 3 shows the arrangement of the strain gauges, repeated on both surfaces of the beam. The deflection is measured with displacement transductors.

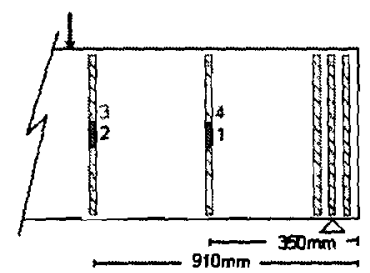

Control beem

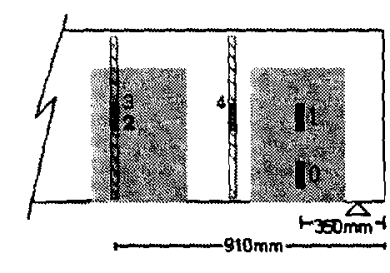

Specod U-sheoed reintercemert

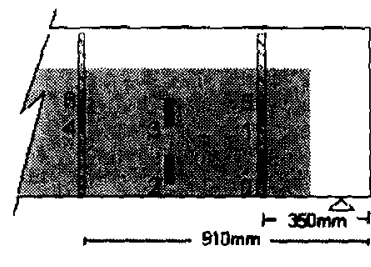

Continuous U-shepeci reintorcentert

Figure 3. Strain gauges location

\subsection{Test procedure}

Two ultimate failure tests per beam are carried out as follows:

- long-span beam: the first test is carried out on the whole beam with a $4300 \mathrm{~mm}$ span, on which a single load is placed at a distance from the support that equals three times the beam depth;

- short-span beam: in the second test, the span is limited by shifting the support to the point where the load was placed in the first test and the load is applied at a distance from the support that equals 2.5 times the beam depth.

\section{Results}

Table 2 shows the ultimate load obtained in the tests together with the theoretic values obtained by the methods of the FIB, Teng and Monti. It is observed that through the Teng and Monti models the values obtained are more conservative than those obtained applying the FIB formulation.

Figure 4a clearly shows the increase in the load capacity of the beams strengthened with FRP compared with the control beams (this can also be observed in Table 2, even for beams made of a lower-strength concrete), without presenting a significant stiffness increase. Similarly, Figure $4 \mathrm{~b}$ shows a comparison between two beams strengthened with FRP, one using a continuous strengthening and the other applying $500 \mathrm{~mm}$ spacing. No significant increase is observed of either the load capacity or the beam stiffness. 
Table 2. Maximum Loads

\begin{tabular}{|c|c|c|c|c|c|}
\hline \multirow{2}{*}{ Specimen } & $f_{\mathrm{cm}}$ & \multicolumn{3}{|c|}{ Theoretic Values } & Experimental Values \\
\hline & $M P a$ & \multicolumn{3}{|c|}{ Ultimate load $k N$} & Ultimate Load $k N$ \\
\hline $\overrightarrow{\mathrm{V} 1 \mathrm{P}}(\mathrm{L})$ & 36.95 & \multicolumn{3}{|c|}{193.29} & 202.74 \\
\hline \multirow[t]{2}{*}{$\mathrm{V} 1 \mathrm{P}(\mathrm{C})$} & 36.95 & \multicolumn{3}{|c|}{211.28} & 235.63 \\
\hline & & FIB & Teng et al. & Monti & \\
\hline V2-U90-S600(L) & 36.95 & 329.37 & 252.04 & 275.70 & 341.00 \\
\hline V2-U90-S600(C) & 36.95 & 358.24 & 274.73 & 300.28 & 327.13 \\
\hline V3-U90-C600(L) & 24.47 & 321.35 & 240.61 & 289.07 & 299.00 \\
\hline V3-U90-C600(C) & 24.47 & 349.58 & 262.39 & 314.73 & 291.00 \\
\hline V5-U90-C600(L) & 22.64 & 314.04 & 235.95 & 281.95 & 336.10 \\
\hline V5-U90-C600(C) & 22.64 & 382.00 & 287.71 & 343.25 & 372.20 \\
\hline V8-U90-S600(L) & 20.50 & 277.47 & 217.39 & 231.19 & 325.70 \\
\hline V8-U90-S600(C) & 20.50 & 337.85 & 265.30 & 281.97 & 378.50 \\
\hline
\end{tabular}

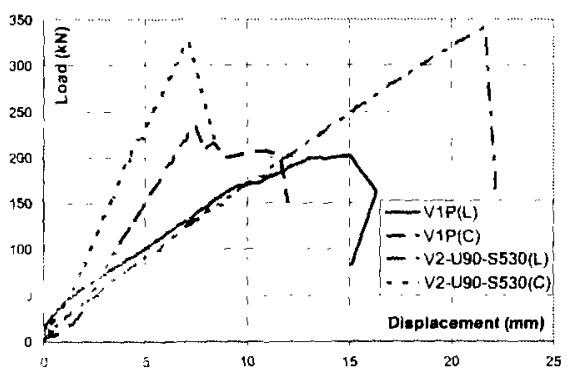

a)

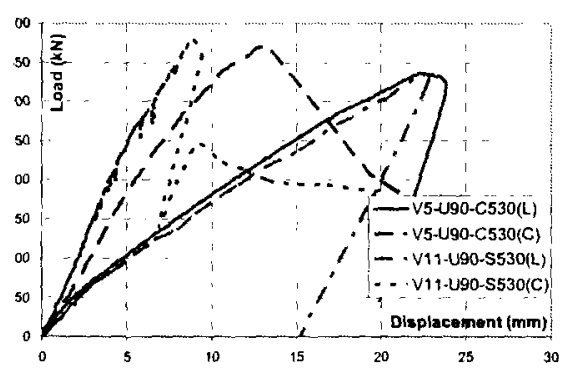

b)

Figure 4. Load vs displacement of the tested beams

Figure 5 shows how the stirrups of the control beam virtually reach their ultimate failure deformation, while the stirrups of the strengthened beam barely reach their yield point. Moreover, we can observe that the point of the transverse reinforcement activation in the control beam occurs under a smaller load than in the case of the beam strengthened with FRP. 


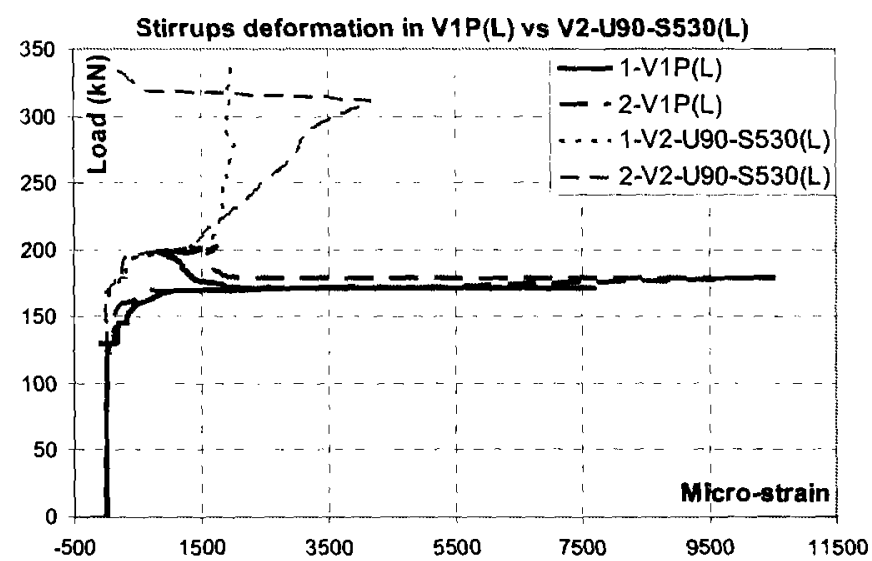

Figure 5. Stirrups strain of VPI(L) vs V2-U90-S600(L)

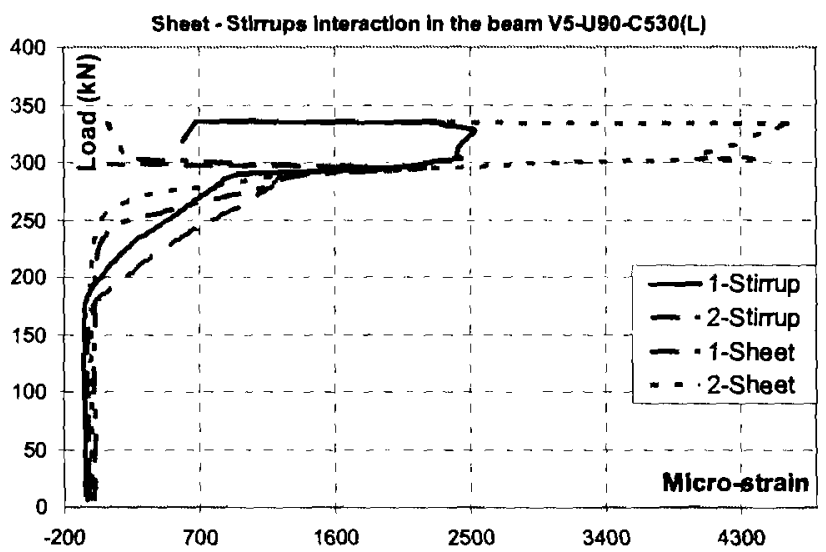

Figure 6. Strain of stirrups and carbon fibre measured in the same point

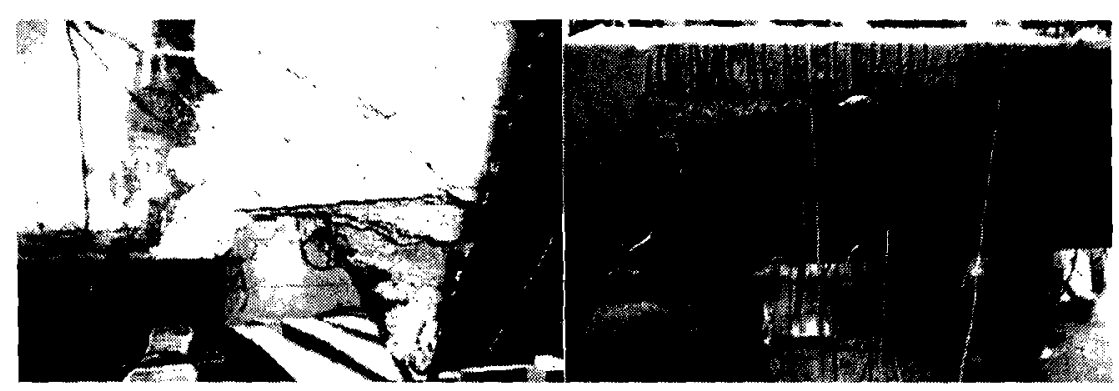

Figure 7. Failure mode of the tested beams 
In Figure 6 we can see that the point of activation of the stirrups occurs under a slightly smaller load than the point of the fibre activation. In most cases presented here, the steel does not reach the yield point before the FRP delamination, in which moment the load is transferred to the stirrups leading them to their ultimate strain.

The failure mode in all reinforced beams was by FRP delamination with concrete cover separation (Figure 7).

\section{Conclusions}

As previous conclusions that can be drawn out from the small number of test carried out up to date is possible indicate the following ones:

- shear strengthening with CFRP sheet enhances significantly shear capacity of the beam; especially for the configuration of completely wrapping section. But it does not increase in the stiffness;

- the steel stirrups in the cracked area yield before failure and, therefore, it seems to be valid that the total shear capacity could be seen as the sum of the contributions of the concrete, stirrups and CFRP;

- in all the $U$-wrapped beams the failure occurs by delamination before reaching the ultimate strain of the CFRP

\section{Acknowledgments}

These works are part of the Projects financed by the Spanish Ministry of Public Vore ...: $9010 / A 04$ and by the Ministry of Science and Innovation ref. BIA200767790-C02. This works includes a Research Staff Training grant (FPI), ref. BES200612211. To Sika and Basf, for providing the material and advise for beam strengthening.

These works were done by the Eduardo Torroja Institute for Construction SciencesCSIC in collaboration with the Technical University of Madrid.

\section{References}

CEB-FIP Model Code 1990, Comité euro-international du béton, Bulletin d'information $n^{\circ} 213 / 214,1993$.

FIB Externally bonded FRP reinforcement for RC structures, Fédération internationale du béton, TG 9.3, Bulletin 14, Lausanne, Switzerland, 2001.

Monti G., Lionta M., "Test and design equations for FRP strengthening in shear, Construction and building materials", Construction and Building Materials, vol. 21, $\mathrm{n}^{\circ}$ 4, 2006, p. 799-809.

Teng J., Chen J., Smith S., Lam L., FRP Strengthened RC Structures, John Wiley and Sons, 2002, p. 103-134.

Zsutty T.C., "Shear strength prediction for separate categories of simple beam tests", $A C I$ Journal, Proceedings, vol. 68, ${ }^{\circ} 2$, February 1971, p. I38-143. 